\title{
$\widehat{A}$ Madridge \\ madridge Journal of Dentistry and Oral Surgery \\ Interconnecting Scientific World
}

Open Access

\section{Immediate Obturator with Airway for Maxillary Resection Surgery: A Case Report}

\author{
Hamit Serdar Çötert ${ }^{1 *}$, Ayse Gozde Türk² ${ }^{2}$ Raşit Midilli ${ }^{3}$, and Sercan Gode ${ }^{4}$ \\ ${ }^{\prime}$ Professor, Department of Prosthodontics, Faculty of Dentistry, Ege University, Izmir, Turkey \\ ${ }^{2}$ Research Assistant, Department of Prosthodontics, Faculty of Dentistry, Ege University, Izmir, Turkey \\ ${ }^{3}$ Professor, Department of Otorhinolaryngology, Faculty of Medicine, Ege University, Izmir, Turkey \\ ${ }^{4}$ Associate Professor, Department of Otorhinolaryngology, Faculty of Medicine, Ege University, Izmir, Turkey
}

\section{Article Info}

\author{
*Corresponding author: \\ Hamit Serdar Çötert \\ Professor \\ Department of Prosthodontics \\ Faculty of Dentistry \\ Ege University \\ Izmir, Turkey \\ Tel: +902323114651 \\ E-mail: cotert@gmail.com
}

Received: December 8, 2017

Accepted: January 9, 2018

Published: January 16, 2018

Citation: Çötert HS, Türk AG, Midilli R, Göde S. Immediate Obturator with Airway for Maxillary Resection Surgery: A Case Report. Madridge J Dent Oral Surg. 2018; 3(1): $80-84$.

doi: $10.18689 / \mathrm{mjdl}-1000119$

Copyright: @ 2018 The Author(s). This work is licensed under a Creative Commons Attribution 4.0 International License, which permits unrestricted use, distribution, and reproduction in any medium, provided the original work is properly cited.

Published by Madridge Publishers

\section{Introduction}

Resective surgery, namely the maxillectomy, is the main part of the treatment of maxillary neoplasms in combination with radiotherapy and/or chemotherapy [1]. Radical maxillectomy operations lead to surgical defects having harmful effects on the physiologic abilities of patients [2-4]. Oral feeding may almost be impossible and naso-gastric tubing may required after resection surgery [5-9]. Speech intelligibility is also impaired [10-13], facial contours may unaesthetically change [14] and the psychological condition deteriorates $[3,4,14]$. The immediate oral rehabilitation of such patients is provided by surgical obturators to facilitate healing process, recover the stomatognathic functions and esthetics, prevent the surgical defect from food and liquids and avoid the patient from the psychosocial impairments $[4,15]$. Surgical immediate obturators were used along the first week postoperatively, and then were replaced with a interim obturator in removable manner. Palatal plate of the surgical obturator can easily be modified and used as an interim obturator [16-18]. Benefits of the surgical obturators were described in several report $[2-4,8,11-13,15,19]$. Dressing and the obturation of the surgical cavities have been performed with a variety of appliances and materials; including gauze pads [2,3,8], sponges [20], inflatable bulbs [21], thermoplastic materials $[22,23]$, tissue conditioning materials [4], and elastomeric materials [24,25]. Surgical obturators have been secured to the remaining teeth with ligature wires, clasps or hinged gates $[2,3,19,26,27]$. Circumzygomatical [19] or transnasal [20] ligatures [4,5,15,20], screws and mini-implants $[24,28,29]$ have been employed and recommended for edentulous cases in reviewed literature. However, weight has been reported as a major concern influencing surgical obturator success especially in cases with larger defects. Various lightweight surgical obturator designs consisting hollow structures were described in order to reduce the obturator weight [30-32]. Moreover, neither hollow, nor solid obturators permit nasal breathing. The aim of this case report is to describe a quick and easy lightweight immediate obturator permitting nasal respiration for maxillary resection defects.

Keywords: Obturator; Radical Maxillectomy; Resection Surgery.

\section{Case Outline}

A 49-year-old male patient was referred from the Ege University, Medical Faculty Hospital, Department of Otorhinolaryngology and Head-Neck Surgery for the preoperative preparation procedures. Radical maxillectomy operation had been planned on the right side in order to the excision of the epidermoid carcinoma originated from the maxillary sinus epithelium and filled the whole sinus. Medical history was taken. Extra oral and intra oral inspections were made and recorded. Attention was paid to the susceptible teeth exhibiting the carious lesions, endodontic impairment or mobility. Teeth surfaces were scaled. Calculi 
were removed and the oral hygiene was improved as possible. Preliminary impressions were made with an irreversible hydrocolloid impression material (CA 37, Cavex Holland BV, Haarlem, The Netherlands) by using stock trays and maxillomandibular relationship was recorded. Impressions were poured with type III dental stone (Elite Model, ZhermackSpA, Badia, Polesine, Italy) and the master casts were obtained. Estimated surgical margins were outlined on the master cast in consultation with the surgery team. Maxillary and mandibular casts were mounted on a hinge-type articulator by using maxillomandibular relation records. Teeth in the resection area were cut off, and edentulous alveolar ridge morphology was established in the forthcoming resection area of the master cast. Palatal anatomy was established as symmetric as possible with the nonresected side to facilitate speech and deglutition after surgery. Attention was paid to the amount of vertical reduction to prevent occlusal interference, and also to the horizontal reduction to optimize the tension of the labial and/or facial flap. A palatal plate was made with auto polymerizing acrylic resin (Imicryl SC; Imicryl, Konya, Turkey) in order restore the palatal integrity and to reproduce palatal contours. Plate was trimmed, finished and polished in conventional manner. Interproximal extensions of the palatal plate were perforated by using steel round burn \#4 (Meisinger $\mathrm{GmbH}$, Neuss, Germany) to wire to the remaining teeth at the time of surgery.

Palatal plate and the ligature wires were autoclaved prior to the operation. Putty silicone elastomer (Speedex, ColtèneWhaledent AG, Alstätten, Switzerland) taken from the freshly opened new can, was immersed in a disinfectant solution (Cidex OPA, Johnson \& Johnson, East Windsor, NJ, USA) for 30 minutes. Resection was completed, haemostasis was established and deep undercuts of the surgical cavity were blocked out by using gauze pads impregnated with antibacterial pomade (Furacin Soluble Dressing, Eczacıbaşı, Istanbul, Turkey) (Figure 1). Remaining walls of the cavity were also lined with a thin layer of same material in order to protect the surfaces from the direct contact with elastomer. Palatal plate was tried in-situ. Silicon putty was hand kneaded and put into the superior half of the cavity. Index finger of the left hand was laid on the inferior surface of the elastomer as to point the posterior nasal aperture, and kept in position till the putty elastomer has set (Figure 2). Inferior surface of the hardened putty elastomer was isolated with antibacterial pomade (Furacin). Second portion of the putty silicone elastomer was hand kneaded again. Index finger of the left hand was repositioned in previous place and the remaining inferior halve of the surgical cavity was filled with putty elastomer (Figure 3). Palatal plate was inserted and the excess putty elastomeric material was taken out. Labial and buccal surfaces of the putty elastomer were contoured in order to support the facial tissues of the labio-jugal flap but do not stretch. Attention was paid to establish an airway in a proper position passing through the elastomeric supra structure from the anterior nasal vestibule to the rhinopharynx. Palatal plate was secured around the teeth by using circumferential ligatures (Dentaurum, Ispringen, Germany) in $0.5 \mathrm{~mm}$ diameter, by employing a needle holder. Excess parts of them were cut off, the remaining tips were pig-tail twisted and pushed into the proximal embrasures in order to avoid mucosal irritations. Labiojugal flap was reposed to its anatomic position as to cover the surgical site and the immediate obturator and secured with multiplanar sutures (Figure 4).

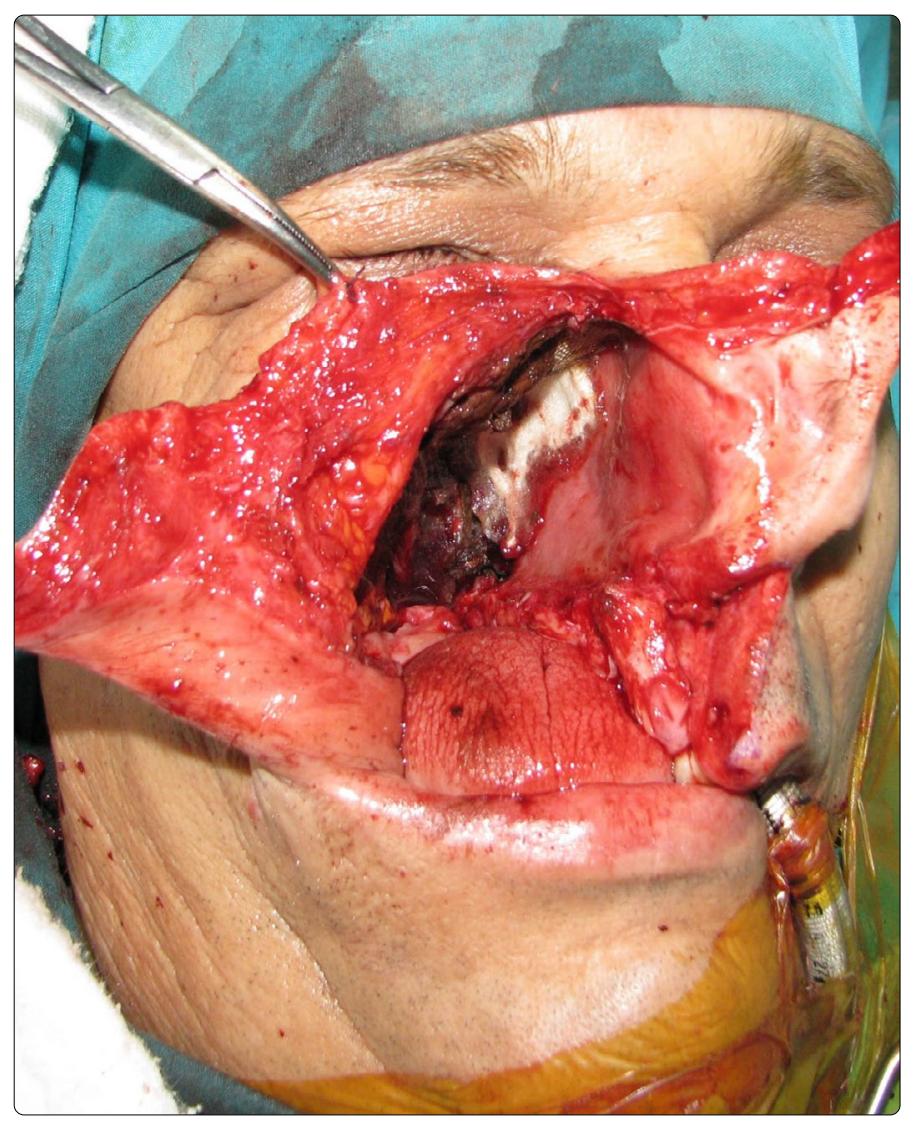

Figure 1. Surgical cavity.

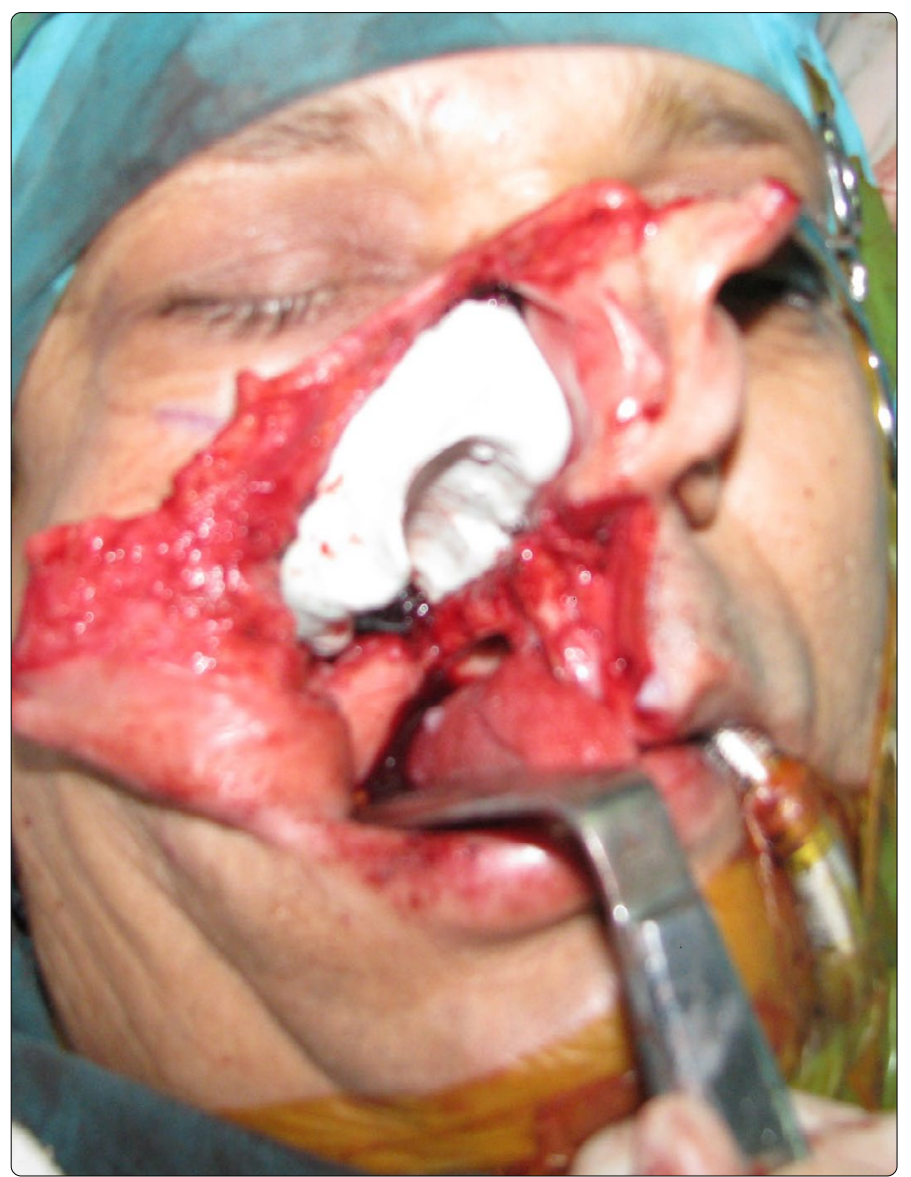

Figure 2. First part of the putty elastomer obturator including nasal airway passage, formed by index finger. 


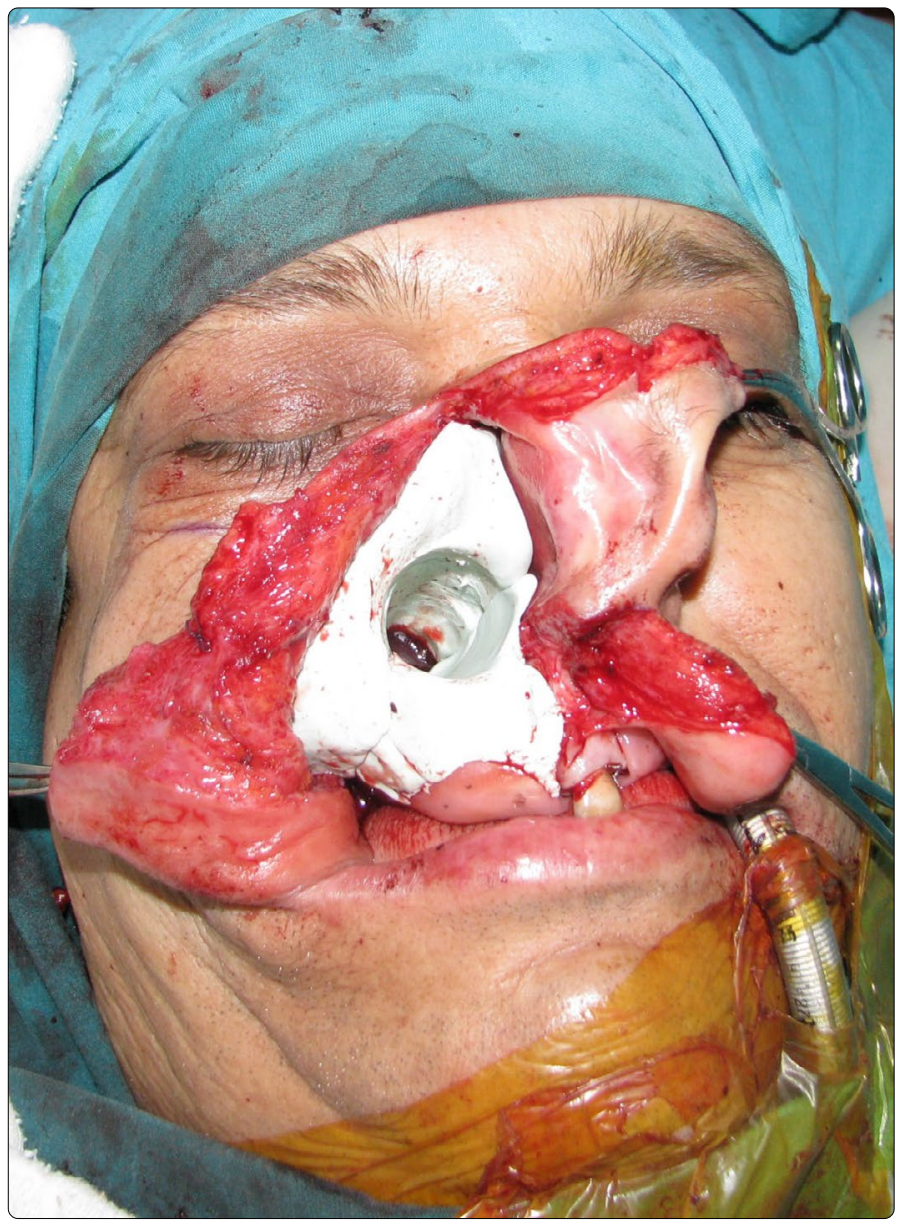

Figure 3. Second part of putty elastomer was inserted to the bottom of the cavity.

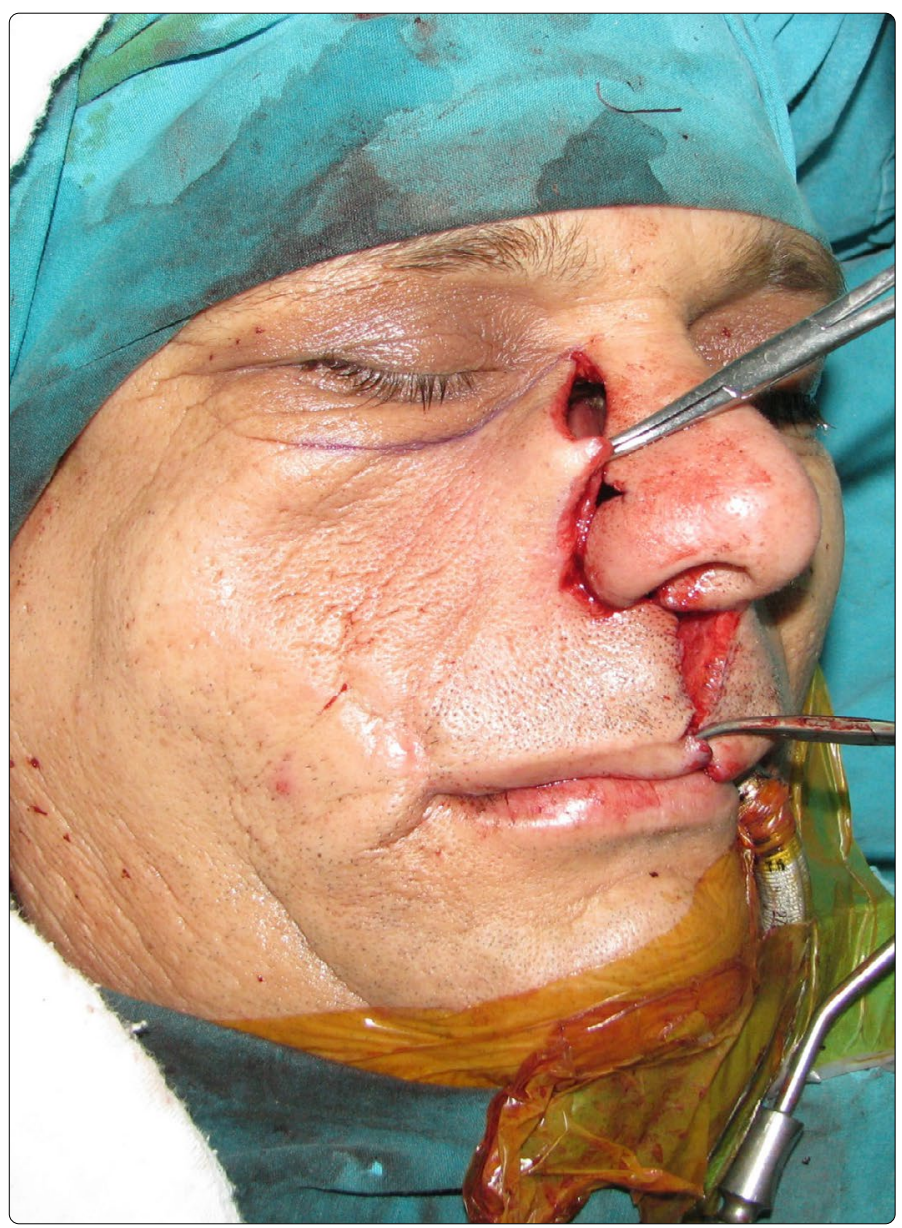

Figure 4. Closure of flaps.
During 7 days postoperatively, patient has been requested to provide daily care by himself by brushing the teeth with a soft brush soaked in a polyvinyl pirolidon-iode antiseptic solution (Batticon, Adeka, Samsun, Turkey) twice a day, and rinse with the same antiseptic 1/2diluted with isotonic natriumchlorure solution four times a day. Removal of the surgical obturator was performed easily and a traumatically with the help of its sectional nature consisting two-pieces. The patient expressed that nasal breathing was comfortable during the first week of the postoperative period. Surgical obturator was used for a week and replaced with an interim obturator in eighth day. Palatal plate of the surgical obturator was modified and used again as an interim obturator.

\section{Discussion}

In recent practice immediate prosthetic obturation of the maxillary resection defects has become a standard care [19]. The primary goals of the immediate obturation of the surgical cavities were reported as to protect the wound from oral contamination, to support the surgical pack, to support the skin grafts if present, to permit deglutition and eliminating the need for nasogastric tubing, to protect the speech intelligibility, to avoid unesthetical healing of the labio-jugal flap, reducing the psychological impact of surgery, minimizing the period of hospitalization $[1,2,4-8,10,14,20]$. It is reported that, immediately obturated maxillary resection patients recovered more quickly than delayed ones $[3,19]$ and were less prone to post-operative facial contracture [14]. However, traditional type of surgical obturators consisting gauze packor sponge surgical dressing and acrylic resin palatal plate create hygienic and esthetic problems since, gauze pack and sponge cannot be able to protect their initial shape. Furthermore, their amorphous and absorbent behavior creates an anaerobic environment causes mal-odor $[17,18]$. It is stated the nonporous nature of the putty silicone elastomeric material does not absorb secretions and prevents accumulation of mucous and debris and improves the hygienic properties of the obturator $[12,16,22]$. It also gave better aesthetics since the putty keeps the given shape and supports the facial structures. Various types of surgical obturators were described for the maxillary resection cases [9-11,13-15]. Reducing the obturator weight by employing hollow structures was aimed in some of these studies $[16,21,23,26]$. However, management of the nasal respiration tract within the obturator has not been mentioned before.

Present report describes a surgical obturator permitting nasal breathing by providing an airway through putty elastomeric supra-structure. Besides nasal breathing, the airway reduced the obturator weight and improved the patient comfort. In addition, airway allowed passive drainage of exudations towards nasopharynx and nostril. Removal of the obturator was performed more easily due to the two-piece nature in comparison with one-piece solid suprastructures. After the immediate obturation period, palatal plate of the surgical obturator was re-employed as modified as an interim obturator as advised in some studies [30-32]. 
In addition to above-mentioned facilities, described surgical obturator with airway, has also presented the well-known classical benefits of the solid putty elastomeric surgical obturators. It didn't let to feeding, speaking and psychosocial impairments. It was hygienic because of the non-porous and non-absorbent surface characteristic of the putty elastomer. It supported the facial flap and protected the contour of the mid face properly. But also gave comfortable breathing during recovery phase to the patient. It was lightweight, facilitated to draining of the exudations from the operational site and easy to remove and did not need any additional material and/or instrumentation. Further studies are required to compare the prognosis of this new method with other obturator materials such as tissue conditioning material containing a breathing passage.

One major concern may rise about this modification. Creating a nasal passage doesn't mean to ensure all benefits of normal nasal breathing. This new passage lacked mucocilliary activity, thus secretions could only be passively drained. Furthermore, lack of humidification and warming functions of nasal breathing were similarly could not be restored. However, allowing passage of the air through the nasal cavity may potentially restore oral, nasopharyngeal and oropharyngeal comfort. Breathing through nasopharynx, have potential benefits for oral nutrition, swallowing and hygiene.

\section{Conclusion}

A modified surgical obturation method for immediate obturation of the maxillary surgical defect is described in this report. Main advantages of this design were observed as the provided nasal breathing through operated side, reduced obturator weight, facilitated draining of the exudations and obturator removal and improved patient comfort in addition to the well known classical benefits of the immediate surgical obturator.

\section{Compliance with Ethical Standards}

\section{Conflict on Interest}

First author H. Serdar Çötert declares that he has no conflict of interest. Second author A. Gözde Türk declares that she has no conflict of interest. Third author RaşitMidilli declares that he has no conflict of interest. Fourth author SercanGöde declares that he has no conflict of interest.

\section{Ethical Approval For Human Participant}

All procedures performed in this study involving a human participant were in accordance with the ethical standards of the institutional and/or national research committee and with the 1964 Helsinki declaration and its later amendments or comparable ethical standards.

\section{Informed Consent For Human Participant}

Informed consent was obtained from the participant included in the study and submitted as translated to English language.

\section{References}

1. Kermer C, Poeschl PW, Wutzl A, Schopper C, Klug C, Poeschl E. Surgical treatment of squamous cell carcinoma of the maxilla and nasal sinuses. J Oral Maxillofac Surg. 2008; 66(12): 2449-53. doi: 10.1016/j.joms.2008.07.016

2. Kazanoğlu A. Inserting a surgical obturator. J Mo Dent Assoc. 1977; 57(8): 19-22.

3. Frame RT, King GE. A surgical interim prosthesis. J Prosthet Dent. 1981; 45(1): 108-10. doi: 10.1016/0022-3913(81)90021-4

4. Keyf F. Obturator prostheses for hemimaxillectomy cases. J Oral Rehabil. 2001; 28: 821-9. doi: 10.1111/j.1365-2842.2001.00754.x

5. Goiato MC, Tamae AC, Silva Pl, et al. Oral rehabilitation after surgical removal of pleomorphic adenoma. J Craniofac Surg. 2011; 22: 1996-9. doi: 10.1097/SCS.0b013e31823195fb

6. Sinha D, Banerjee $S$, Chowdhury $S$. Fabrication of an immediate surgical obturator for a patient with resection of the maxillary antrum and bony orbital floor. J Prosthet Dent. 2014; 112: 376-8. doi: 10.1016/j. prosdent.2013.09.030

7. Tirelli G, Rizzo R, Biasotto M, et al. Obturator prostheses following palatal resection: clinical cases. Acta Otorhinolaryngolltal. 2010; 30: 33-9.

8. Huryn JM, Piro JD. The maxillary immediate surgical obturator prosthesis. J Prosthet Dent 1989; 61: 343-7. doi: 10.1016/0022-3913(89)90142-X

9. Garg AK, Malo M, Dorado LS, Duarte F. Postsurgical management with maxillary obturators after maxillectomy. Gen Dent. 1998; 46: 75-8.

10. Seignemartin CP, Miranda ME, Luz JG, Teixeira RG. Understandability of Speech Predicts Quality of Life Among Maxillectomy Patients Restored With Obturator Prosthesis. J Oral Maxillofac Surg. 2015; 73: 2040-8. doi: 10.1016/j.joms.2015.04.031

11. Mahanna GK, Beukelman DR, Marshall JA, Gaebler CA, Sullivan M Obturator prostheses after cancer surgery: an approach to speech outcome assesment. J Prosthet Dent. 1998; 79: 310-6. doi: 10.1016/S00223913(98)70243-4

12. Rieger J, Wolfaardt J, Seikaly $H$, Jha N. Speech outcomes in patients rehabilited with maxillary obturator prostheses after maxillectomy: a prospective study. Int J Prosthodont. 2002; 15: 139-44.

13. Arigbede AO, Dosumu OO, Shaba OP, Esan TA. Evaluation of speech in patients with partial surgically acquired defects: pre and post prosthetic obturation. J Contemp Dent Pract. 2006; 15: 89-96.

14. Türkaslan S, Baykul T, Aydın MA, Özarslan MM. Influence of immediate and permanent obturators on facial contours: a case series. Cases J. 2009; 3: 6-9. doi: 10.1186/1757-1626-2-6

15. Lapointe HJ, Lampe HB, Taylor SM. Comparison of maxillectomy patients with immediate versus delayed obturator prosthesis placement. J Otolaryngol. 1996; 25: 308-12.

16. Mukohyama $H$, Sasaki $M$, Taniguchi $H$. Chairside modification of a surgical obturator: a clinical report. J Prosthet Dent. 2004; 91: 518-20. doi: 10.1016/ S0022391304001787

17. Wolfaardt JF. Modifying a surgicalobturator prosthesis into an interim obturator prosthesis. A clinical report. J Prosthet Dent. 1989; 62: 619-21. doi: 10.1016/0022-3913(89)90577-5

18. Penn M, Grossmann $Y$, Shiffmann A. A preplanned surgical obturator prosthesis for alternative resection lines in the anterior region. $J$ Prosthet Dent. 2003; 90: 510-3. doi: 10.1016/S0022-3913(03)00532-8

19. Omondi $\mathrm{BI}$, Guthua SW, Awange DO, Odhiambo WA. Maxillary obturator prosthesis rehabilitation following maxillectomy for ameloblastoma: case series of five patients. Int J Prosthodont. 2004; 17: 464-8.

20. Marker P, Svane-Knudsen V, Jorgensen KE, Nielsen A, Hansen O. Immediate obturation of the surgical defect after partial maxillectomy in the edentulous patient. Acta Oncol. 1997; 36: 41-4. doi: 10.3109/02841869709100730

21. Payne AG, Welton WG. An inflatable obturator for use following maxillectomy. J Prosthet Dent. 1965; 15: 759-63. doi: 10.1016/00223913(65)90049-1 
22. Didier $M$, Laccoureye $O$, Brasnu $D$, Vignon M. New surgical obturator prosthesis for hemimaxillectomy patients. J Prosthet Dent. 1993; 69: 5203. doi: 10.1016/0022-3913(93)90163-I

23. Ducic $Y$. An effective, inexpensive, temporary surgical obturator following maxillectomy. Laryngoscope. 2001; 111: 356-8. doi: 10.1097/00005537200102000-00030

24. Ekstrand K, Hirsch JM. Malignant tumors of the maxilla: virtual planning and real time rehabilitation with custom-made R-zygoma fixtures and carbon-graphite fiber-reinforced polymer prosthesis. Clin Implant Dent Relat. Res 2008; 10: 23-9.

25. Blitzer A, Lane EM. Immediate silastic surgical obturator. Laryngoscope. 1983; 93: 1485. doi: 10.1288/00005537-198311000-00019

26. Black WB. Surgical obturation using a gated prosthesis. J Prosthet Dent. 1992; 68: 339-42. doi: 10.1016/0022-3913(92)90341-7

27. Haraguchi $M$, Mukohyama $H$, Taniguchi $H$. A simple method of fabricating an interimobturator prosthesis by duplicating the existing teeth and palatal form. J Prosthet Dent. 2006; 95: 469-72. doi: 10.1016/j.prosdent.2006.04.004
28. Juntunen K, Kullaa A, Lamberg MA, Vintaniemi J. A new application of a screw-plate for prosthetic reconstruction after bilateral total maxillectomy. Clin Oral Implants Res 1993; 4: 47-50.

29. Bohle GC, Mitcherling WW, Mitcherling JJ, Johnson RM, Bohle GC3rd. Immediate obturator stabilization using mini dental implants. J Prosthodont. 2008; 17: 482-6. doi: 10.1111/j.1532-849X.2008.00321.x.

30. Fischman B. The use of light-cured material for immediate hollow obturator prosthesis. J Prosthet Dent. 1989; 61: 215-6. doi: 10.1016/00223913(89)90377-6

31. Radcliffe GJ, Mady S, Burr R, Cheesman AF, Wilson D. A new immediate temporary lightweight obturator for maxillectomy cavities. $\mathrm{Br} J \mathrm{Oral}$ Maxillofac Surg. 1984; 22: 50-3. doi: 10.1016/0266-4356(84)90008-1

32. Ortegon SM, Martin JW, Lewin JS. A hollow delayed surgical obturator for a bilateral subtotal maxillectomy patient: a clinical report. J Prosthet Dent 2008; 99: 14-8. doi: 10.1016/S0022-3913(08)60003-7 